\title{
Prevention of Bacterial and Fungal Infections in Acute Leukemia Patients: A New and Potent Combination of Oral Norfloxacin and Amphotericin B
}

\author{
Takashi Yamada, Kazuo Dan and Takeo Nomura
}

\begin{abstract}
The effect of a combination regimen using norfloxacin (NFLX) and amphotericin B (AMPHB) for prevention of infections in patients with acute leukemia being treated by remission-induction chemotherapy in a randomized, controlled trial was studied. One hundred and six consecutive, evaluable patients were randomly assigned to receive orally $200 \mathrm{mg}$ of norfloxacin two or four times daily and $200 \mathrm{mg}$ of amphotericin B four times daily, or amphotericin B only. A smaller percentage of patients with bacteriologically-documented infections was observed in the study group compared with the control group $(34.6 \%$ vs $56.9 \% ; P<0.05)$. The mean number of days that the patients received empirical antibiotic therapy was shorter in the study group ( 23 days vs 30 days; $P<0.05)$. The percentage of patients with a gram-negative bacterial infection $(9.6 \%$ vs $27.5 \% ; \mathrm{P}<0.05)$ or a fungal infection $(17.3 \%$ vs $37.3 \% ; \mathrm{P}<0.05)$ was decreased in the study group. This new combination antimicrobial regimen is safe and effective for prevention of gram-negative bacterial as well as fungal infections in patients with acute leukemia being treated with cytotoxic remission-induction chemotherapy.
\end{abstract}

(Internal Medicine 32: 710-715, 1993)

Key words: infection prophylaxis, gram-negative bacterial infection, fungal infection

\section{Introduction}

Infections remain the most important complications in patients with acute leukemia during cytotoxic therapy in spite of the recent development of supportive therapies such as potent antibiotics and colony-stimulating factors (CSFs). Many of these infections are caused by gram-negative bacteria that colonize in the alimentary tract. Thus, selective or total decontamination of the alimentary tract is a useful approach for prevention of infections in these patients (1).

Norfloxacin is an oral quinoline structurally related to nalidixic acid, and its antibacterial spectrum is broader than those of nalidixic acid (2) and trimethoprim/sulfamethoxazol (3), which have been used previously for prevention of infections in granulocytopenic patients $(1,4,5)$. It was reported that oral norfloxacin preserves the anaerobic gastrointestinal flora, thereby maintaining colonization which is resistant to the acquisition of new aerobic bacteria (6). Patients administered this agent for a long period showed no significant hematologic toxicity, gastrointestinal irritability, or other serious adverse effects (7). For these reasons, several controlled trials of norfloxacin prophylaxis in granulocytopenic patients were initiated $(3,6-8)$.

In the randomized, controlled study, we investigated the effect of norfloxacin plus amphotericin B in the prevention of bacterial and fungal infections in patients with acute leukemia being treated by remission-induction chemotherapy.

\section{Patients and Methods}

All adult patients with acute leukemia, newly diagnosed or in relapse, who were admitted to our hospital between 1 January 1988 and 31 March 1991 were randomized to a control group or a group receiving norfloxacin prophylactically. Informed consent was obtained from all patients before starting the study. In the norfloxacin group, $200 \mathrm{mg}$ of norfloxacin was given orally two times or four times daily. In both groups, oral amphotericin B ( $800 \mathrm{mg} /$ day) was added to prevent colonization of the alimentary tract by yeasts. The prophylactic treatment was started shortly before cytotoxic treatment was initiated and ended when the granulocyte count recovered to more than $1,000 / \mu \mathrm{l}$. The chemotherapeutic agents used were com-

From the Third Department of Internal Medicine, Nippon Medical School, Tokyo

Received for publication June 18, 1993; Accepted for publication September 16, 1993

Reprints should be addressed to Dr. Takashi Yamada, the Third Department of Internal Medicine, Nippon Medical School, 1-1-5 Sendagi, Bunkyo-ku, Tokyo 113 
binations of doxorubicin, vincristine and prednisolone for acute lymphoblastic leukemia, and combinations of behenoyl cytosine arabinoside, daunorubicin, 6-mercaptopurine and prednisolone for acute myelogenous leukemia.

Clinical evaluations and complete blood counts were performed daily, and chemical studies were repeated as needed. The onset of fever or signs of infection prompted institution of intravenous antibiotics empirically. Febrile episodes were defined as the development of a fever above $38^{\circ} \mathrm{C}$ without an allergic reaction due to transfusion or drugs. Infectious complications were defined as bacteriologically and clinically documented infections or septicemia. Episodes accompanied by definite clinical signs and symptoms of infection plus microbiologic confirmation were termed "bacteriologicallydocumented infections." Episodes accompanied by definite clinical signs and symptoms of infection without microbiologic confirmation were termed "clinically-documented infections." The criteria for diagnosis of infectious diseases were as follows. Pneumonia was diagnosed on the basis of a fever and cough with infiltrates on chest roentogenograms, excluding those with the appearance of atelectasis or pulmonary edema. Tracheobronchitis or upper respiratory tract infection were diagnosed on the basis of a fever and cough without infiltrates on chest roentogenograms. Urinary tract infection was defined as pyuria of greater than $10^{5}$ colony-forming units of bacteria per milliliter of urine. Gastrointestinal infection was diagnosed on the basis of a fever with persistent watery diarrhea which was not due to antibiotics or cytotoxic agents and the absence of any other site of infection. Septicemia was defined as at least one blood culture yielding an organism considered to be a pathogen. Clinical diagnoses of perianal abscess, phlegmon, oral candidiasis, phlebitis, and otitis media were made by the attendant physicians. We also recorded unexplained febrile episodes with a body temperature of greater or equal to $38^{\circ} \mathrm{C}$ without any clear site of infection.

\section{Statistical methods}

Mean values were compared by Student's t-test. Differences in proportions between groups were analyzed by the chi-square test with Yates' correction. The times to the first febrile episode were compared by Kaplan-Meier plots and analyzed by the generalized Wilcoxon test.

\section{Results}

\section{Patient characteristics}

One hundred and eleven patients were randomly assigned to the norfloxacin group (norfloxacin plus amphotericin B) or the control group (amphotericin B only). Patients without cytotoxic therapy and patients who died within a week after starting the chemotherapy were excluded, resulting in 106 patients being evaluated (53 patients in each group).

The characteristics of the patients are shown in Table 1. There were no differences between the two groups in terms of the age, sex, subtype of leukemia, status of disease, antileukemic chemotherapy, duration of neutropenia $(<1,000 / \mu \mathrm{l})$, granulocyte
Table 1. Characteristics and Outcome of 106 Eligible Patients with Acute Leukemia Receiving Induction Chemotherapy

\begin{tabular}{|c|c|c|c|}
\hline & & Norfloxacin & Control \\
\hline \multicolumn{2}{|l|}{ Patient number } & 53 & 53 \\
\hline \multicolumn{2}{|l|}{ Median age } & 49 & 39 \\
\hline Female & $\mathrm{n}$. & 21 & 26 \\
\hline Male & n. & 32 & 27 \\
\hline \multicolumn{4}{|l|}{ Diagnosis } \\
\hline ALL & n. & 12 & 11 \\
\hline AML & n. & 31 & 32 \\
\hline hybrid & n. & 1 & 2 \\
\hline AML/MDS & n. & 9 & 8 \\
\hline \multicolumn{4}{|l|}{ Disease status } \\
\hline initial diagnosis & $\mathrm{n}$. & 36 & 28 \\
\hline relapse & $\mathrm{n}$. & 17 & 25 \\
\hline \multicolumn{3}{|l|}{ Mean duration of } & 38 \\
\hline \multicolumn{4}{|c|}{$\begin{array}{l}\text { Mean duration of neutropenia } \\
\text { with granulocyte count }\end{array}$} \\
\hline$<100$ & day & 17 & 18 \\
\hline$<500$ & day & 26 & 27 \\
\hline$<1,000$ & day & 31 & 34 \\
\hline Complete remission & n. & 25 & 28 \\
\hline \multicolumn{2}{|c|}{ Death during treatment $\mathrm{n}$. } & 11 & 10 \\
\hline
\end{tabular}

ALL: acute lymphoblastic leukemia, AML: acute myelogenous leukemia, AML/MDS: AML transformed from myelodysplastic syndrome

count or study duration. Although there were more relapsed patients in the control group, the incidence of infection was not significantly different among the initially diagnosed patients and relapsed patients, in either the control group or the norfloxacin group. The outcome, in terms of the rate of complete remission and the number of deaths during the study period, was similar in both groups. The characteristics of the patients were similar in the two groups of patients given $400 \mathrm{mg} / \mathrm{day}$ and $800 \mathrm{mg} /$ day of norfloxacin. We combined and analyzed these two groups of patients, since the prophylactic effect was not significantly different between these two groups.

\section{Febrile episodes and frequency of infection}

One patient in the norfloxacin group and two in the control group were febrile at the time of initiating remission-induction chemotherapy, and the fever persisted throughout the study period. For this reason, these three patients were excluded from the analysis of febrile episodes. Three patients in the norfloxacin group and five in the control group who were febrile at the time of initiating the chemotherapy and became afebrile soon after were included in the analysis. The data on febrile episodes are compiled in Table 2. Febrile episodes occurred in 38 of 52 patients in the norfloxacin group and 44 of 51 in the control group. Febrile episodes occurred 52 times in the norfloxacin 


\section{YAMADA et al}

Table 2. Febrile Episodes

\begin{tabular}{|c|c|c|c|c|}
\hline & \multicolumn{2}{|c|}{ Norfloxacin } & \multicolumn{2}{|c|}{ Control } \\
\hline & $\begin{array}{l}\text { Num } \\
\text { patients }\end{array}$ & $\begin{array}{l}\text { er of } \\
\text { episodes }\end{array}$ & $\begin{array}{r}\text { Nun } \\
\text { patients }\end{array}$ & $\begin{array}{l}\text { ber of } \\
\text { episodes }\end{array}$ \\
\hline Patients analyzed & 52 & & 51 & \\
\hline All patients with fever & 38 & 52 & 44 & 74 \\
\hline $\begin{array}{l}\text { Clinically-documented } \\
\text { infection }\end{array}$ & 23 & 29 & 24 & 28 \\
\hline $\begin{array}{l}\text { Bacteriologically- } \\
\left.\text { documented infection }{ }^{a}\right)\end{array}$ & 16 & 20 & 22 & 36 \\
\hline Septicemia ${ }^{\text {b) }}$ & $3 *$ & 3 & $10^{*}$ & 10 \\
\hline a) or b) & $18^{\dagger}$ & 23 & $29^{\dagger}$ & 43 \\
\hline
\end{tabular}

*P $<0.10$; determined by the chi-square test with Yates' correction, ${ }^{\dagger} \mathrm{P}<0.05$; determined by the chi-square test with Yates' correction.

group compared with 74 times in the control group. The mean number of febrile episodes in one patient during the study period was 1.0 in the norfloxacin group and 1.4 in the control group, with a statistically significant difference $(\mathrm{P}<0.05)$.

In the norfloxacin group, febrile episodes occurred in 26 of 36 previously untreated patients and in 12 of 16 relapsed patients. In the control group, febrile episodes occurred in 22 of 28 previously untreated patients and 22 of 23 relapsed patients. There were no statistical differences in the incidences of infection between each disease status in the norfloxacin group as well as in the control group. Septicemia tended to occur more frequently in the control group compared with the norfloxacin group (10 versus 3 patients), but this was not statistically significant $(\mathrm{P}<0.10)$. Bacteriologically-documented infection or septicemia occurred in 18 and 29 patients $(\mathrm{P}<0.05)$, and the numbers of those episodes were 23 and 43 times, in the norfloxacin group and the control group, respectively. In Table 2, afebrile episodes of oral candidiasis were excluded from the category of "bacteriologically-documented infection."

The cumulative percentages of afebrile patients after induction chemotherapy are shown in Fig. 1. Four patients in the norfloxacin group and six in the control group who were febrile at the time of initiating chemotherapy were excluded from this analysis, although three and four of them in the respective groups became afebrile soon after initiating the chemotherapy. Patients were considered censored if they went off the study without a fever. Febrile episodes occurred more rapidly in the patients not receiving norfloxacin, with a median time to the first febrile episode of 11 days compared to 18 days in the patients receiving norfloxacin. There was a statistically significant difference between the curve of the norfloxacin group and that of the control group when analyzed by the generalized Wilcoxon test $(\mathrm{P}<0.001)$. The mean numbers of days with a fever were 8.7 days and 11.9 days, and the proportions of febrile time in the study period were $24.1 \%$ and $34.9 \%$ in the norfloxacin group and control group, respectively. There was a statistically

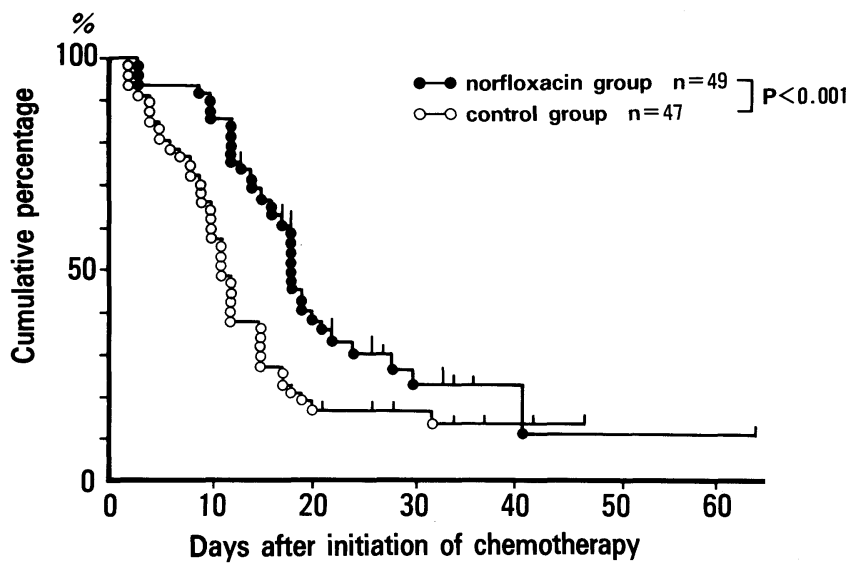

Fig. 1. Cumulative percentage of acute leukemia patients without fever after initiation of remission-induction chemotherapy. The difference in the overall curves between the norfloxacin group (norfloxacin plus amphotericin B) and the control group (amphotericin B only) was statistically significant $(\mathrm{P}<0.001$; generalized Wilcoxon test). Patients who were free of fever during the study period were censored $(\perp)$.

significant difference between these percentages of febrile days $(\mathrm{P}<0.05)$. The mean numbers of days on which patients received empirical antibiotic therapy were 23 and 30 in the norfloxacin and control groups, respectively, and the difference was statistically significant $(\mathrm{P}<0.05)$.

\section{Sites of infection}

The sites of infection are shown in Table 3. Forty-eight and 73 sites of infection were observed in the norfloxacin group and the control group, respectively. Infections of the skin and soft tissue, stomatitis and septicemia were observed more often in the control group, but the difference was not statistically sig-

Table 3. Sites of Infection

\begin{tabular}{|c|c|c|c|c|}
\hline \multirow[b]{2}{*}{ Site } & \multicolumn{2}{|c|}{ Norfloxacin } & \multicolumn{2}{|c|}{ Control } \\
\hline & $\begin{array}{l}\text { Num } \\
\text { patients }\end{array}$ & $\begin{array}{l}\text { er of } \\
\text { episodes }\end{array}$ & $\begin{array}{c}\text { Num } \\
\text { patients }\end{array}$ & $\begin{array}{l}\text { er of } \\
\text { episodes }\end{array}$ \\
\hline Lung & 12 & 12 & 12 & 13 \\
\hline Upper respiratory tract & 12 & 13 & 13 & 15 \\
\hline Urinary tract & 3 & 3 & 4 & 4 \\
\hline Anorectal & 3 & 3 & 4 & 4 \\
\hline Skin and soft tissue & 4 & 5 & 7 & 9 \\
\hline Stomatitis & $5^{*}$ & 5 & $13^{*}$ & 15 \\
\hline Gastrointestinal tract & 2 & 2 & 2 & 2 \\
\hline Septicemia & $3^{\dagger}$ & 3 & $10^{\dagger}$ & 10 \\
\hline Phlebitis & & & 1 & 1 \\
\hline Otitis media & 1 & 1 & & \\
\hline No site found ${ }^{\text {a) }}$ & 10 & 10 & 8 & 8 \\
\hline Totals & 38 & 58 & 44 & 81 \\
\hline
\end{tabular}

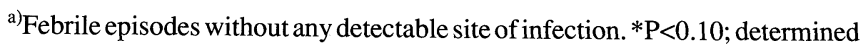
by chi-square test with Yates' correction. ${ }^{\dagger} \mathrm{P}<0.10$; determined by chi-square test with Yates' correction. 
nificant. Life-threatening infections, including pneumonia and septicemia, were observed in 15 patients in the norfloxacin group and 19 patients in the control group.

\section{Bacteriologically-documented organisms}

Table 4 summarizes the organisms causing infections in the patients during the study period. Gram-positive infections occurred in 14 of 52 patients in the norfloxacin group and 17 of 51 in the control group, with no significant difference. Two patients with norfloxacin and four without norfloxacin developed gram-positive septicemia. Staphylococcus aureus, coagulase-negative staphylococci and Enterococcus sp. were the principal gram-positive pathogens in each group. In the cases of pneumonia and other sites of infection, there were no predominant gram-positive pathogens in either patient group.

Gram-negative infections occurred in only five of 52 patients in the norfloxacin group compared with 14 of 51 in the control group. There was a statistically significant difference between these two groups $(\mathrm{P}<0.05)$. Gram-negative septicemia or pneumonia developed in only two patients given norfloxacin and in seven patients without norfloxacin. Pseudomonas aeruginosa and Enterobacter cloacae were the principal gramnegative pathogens in each group.

We detected fungal infections, including Candida stomatitis, in nine of 52 patients in the norfloxacin group and in 19 of 51 in the control group. The difference between these two groups was statistically significant $(\mathrm{P}<0.05)$. In the norfloxacin and control groups, disseminated or invasive fungal infections occurred in four and six patients, respectively. Fungemia occurred only in the control group (two patients), and the pathogen was Trichosporon sp.

\section{Compliance and adverse reactions}

Compliance was similar in the two groups of patients, with ingestion of more than $95 \%$ of the total prescribed doses. Norfloxacin and amphotericin B were well tolerated, and there were no adverse effects which interrupted the study. Only a few patients complained of nausea after taking amphotericin B. Prolonged bone marrow suppression was not observed in the norfloxacin group.

\section{Discussion}

The results of the present study clearly showed the effectiveness of norfloxacin plus amphotericin B for prophylactic use in patients with acute leukemia since this combination 1) decreased the number of patients with bacteriologically-documented infections, including septicemia, 2) decreased the incidence of infections per patient during the study period, 3) prolonged the time to the first febrile episode, 4) reduced the proportion of time in a febrile state during the study period, 5) decreased the number of days on which patients received empirical antibiotic treatment, 6) decreased the number of patients with gram-negative bacterial and 7) fungal infections. Previous reports showed that the number of patients with bacteriologically-documented infections in norfloxacin-treated

Table 4. Identified Causative Organisms of Infection

\begin{tabular}{|c|c|c|c|c|}
\hline & \multicolumn{2}{|c|}{ Norfloxacin } & \multicolumn{2}{|c|}{ Control } \\
\hline & $\begin{array}{l}\text { Patients with } \\
\text { infection (n) }\end{array}$ & $\begin{array}{l}\text { Total number } \\
\text { of infections }\end{array}$ & $\begin{array}{l}\text { Patients with } \\
\text { infection (n) }\end{array}$ & $\begin{array}{l}\text { Total number } \\
\text { of infections }\end{array}$ \\
\hline Gram-positive bacteria & 14 & 17 & 17 & 24 \\
\hline Staphylococcus aureus & 6 & 7 & 7 & 9 \\
\hline Coagulase-negative & & & & \\
\hline staphylococcus & 5 & 5 & 5 & 6 \\
\hline Streptococcus sp. & & & 1 & 1 \\
\hline Enterococcus sp. & 4 & 5 & 6 & 7 \\
\hline Branhamella catarrhalis & & & 1 & 1 \\
\hline Gram-negative bacteria & $5^{*}$ & 6 & $14^{*}$ & 21 \\
\hline Pseudomonas aeruginosa & 3 & 3 & 8 & 9 \\
\hline Pseudomonas cepacia & & & 1 & 1 \\
\hline Escherichia coli & & & 1 & 1 \\
\hline Enterobacter cloacae & 1 & 2 & 4 & 5 \\
\hline Acinetobacter calcoaceticus & & & 2 & 2 \\
\hline Flavobacterium sp. & & & 1 & 2 \\
\hline Moraxella sp. & 1 & 1 & & \\
\hline Hemophillus parainfluenza & & & 1 & 1 \\
\hline Fungi & $9^{\dagger}$ & 10 & $19^{\dagger}$ & 21 \\
\hline Candida sp. & 9 & 9 & 17 & 19 \\
\hline Trichosporon sp. & 1 & 1 & 2 & 2 \\
\hline
\end{tabular}

*P $<0.05$; determined by chi-square test with Yates' correction, ${ }^{\dagger} \mathrm{P}<0.05$; determined by chi-square test with Yates' correction. 
patients was lower $(24 \%$ to $44 \%)(3,6,7,9)$ compared with the control group (57\%) (7) and the group which received nonabsorbable antibiotics (67\%) (6). Moreover, gram-negative bacterial infections occurred significantly less often in the norfloxacin-treated group (0\% to $11.4 \%)(6-8)$ compared with the control group $(24 \%, 39 \%)(7,8)$ and the group which received non-absorbable antibiotics (16.7\%) (6). In the report of Karp et al (8), the mean number of days from starting the chemotherapy to the first febrile episode was longer in the norfloxacin group, and the mean number of days with a fever during the study period was lower in the norfloxacin group compared with the control group. These findings resulted in a lower overall cost of medical care. Karp et al also showed the prophylactic effect of norfloxacin on the time to the first febrile episode in terms of the mean number of days, while we showed this in terms of the median number of days using Kaplan-Meier plots. Because the absorbance of norfloxacin is poor, it can be present at high concentrations in the gastrointestinal tract without necessarily achieving therapeutic levels in the serum (2). Thus, the drug effect is localized to the gastrointestinal tract, a major entry route of gram-negative organisms that can disseminate during intensive chemotherapy. This may explain why the incidence of respiratory tract infections and the number of patients with respiratory tract infections were similar in both groups. There may be other reasons for the very good results of the present study, such as the facts that norfloxacin has a broad antimicrobial spectrum, is poorly absorbed in spite of its high concentration in the gastrointestinal tract, and preserves colonization resistance. Although we didn't have enough data on the surveillance culture and bacteria resistant to norfloxacin, previous reports showed a low prevalence of norfloxacinresistant aerobic bacteria in stool specimens obtained throughout the course of granulocytopenia and indicated that such bacteria appeared to be independent of norfloxacin administration $(7,8)$. Acquired infections in the norfloxacin group were not refractory to the empirical antibiotic treatment, and norfloxacin had no impact on the frequency of gram-positive (including MRSA, Methicillin resistantStaphylococcus aureus) bacterial infections in the present study or in the study of Karp et al (8).

There is substantial evidence in the literature that fungal infections increase in frequency in granulocytopenia $(11,12)$. Because invasive fungal infections are life-threatening in neutropenic patients, their prevention is important. There have been several reports on the prophylactic use of nystatin $(10,13-$ 15) or amphotericin B (16-18), but their effects have been controversial. Since nystatin is of questionable value in decreasing the incidence of fungal infections $(14,15,19)$ and shows poor patient compliance (11), we decided to use amphotericin B for prophylaxis of fungal infections. In the present results, the number of patients who suffered from fungal infections, including oral candidiasis, was significantly lower in the norfloxacin group. This is the first report showing the effectiveness of a combination regimen consisting of norfloxacin plus amphotericin-B in the prophylaxis of fungal infections. Although the reasons why a smaller number of patients with fungal infections was seen in the norfloxacin group are unclear, it may have been due to the smaller number of days with a fever and the less frequent administration of empirical antibiotic treatment in the norfloxacin group or, it may have been due to the fact that norfloxacin preserves colonization resistance, which protects the anaerobes and suppresses the growth of pathogenic aerobes as well as fungi (20). Norfloxacin has no intrinsic antifungal activity, but it has been reported to augment the in vitro antifungal activity of amphotericin $\mathrm{B}$, nystatin and other antifungal agents $(6,21)$. Thus, synergistic activity between norfloxacin and amphotericin B may have been another factor in the prophylactic effect on fungal infections seen in the present study.

Various disadvantages of regimens using oral non-absorbable antibiotics, such as high cost, adverse gastrointestinal effects and poor patient compliance, and a tendency to develop aminoglycoside resistance, have been reported (22). In the present study, there were no adverse side effects from norfloxacin, such as neurotoxicity, which required discontinuation of the study. Norfloxacin and amphotericin B were both well tolerated and enjoyed a high degree of patient compliance. Combination use of norfloxacin and amphotericin B for patients with acute leukemia during remission-induction chemotherapy is more useful for the prophylaxis of gram-negative bacterial and fungal infections, and it reduces the cost of medical care compared with regimens using non-absorbable antibiotics. Recently, it was reported that cytokines, such as granulocyte colony-stimulating factor (G-CSF) and granulocytemacrophage colony-stimulating factor (GM-CSF), shorten the neutropenic period during chemotherapy for hematological malignancies. It is interesting that recent advances in cytokine therapy have aided in the prophylaxis of infection in patients with neutropenia, and this therapy is considered to be useful for prevention of infections when used in combination with an oral prophylactic regimen.

\section{References}

1) Dekker AW, Rozenberg-Arska M, Verhoef J. Infection prophylaxis in acute leukemia: A comparison of ciproxacin with trimethoprimsulfamethoxazole and colistin. Ann Intern Med 106: 7, 1987.

2) Norrby SR, Jonsson M. Antibacterial activity of norfloxacin. Antimicrob Agents Chemother 23: 15, 1983.

3) Bow EG, Rayner E, Louie TJ. Comparison of norfloxacin with cotrimoxazole for infection prophylaxis in acute leukemia. Am J Med 84: 847, 1988.

4) Dekker AW, Rozenberg-Arska M, Sixma JJ, Verhoef J. Prevention of infection by trimethoprim-sulfamethoxazole plus amphotericin B in patients with acute non-lymphocytic leukemia. Ann Intern Med 95: 555, 1981.

5) Wade JC, De Jongh CA, Newman KA, Crowley J, Wiernik PH, Schimpff SC. Selective antimicrobial modulation as prophylaxis against infection during granulocytopenia: trimethoprim-sulfamethoxazole vs. nalidixic acid. J Infect Dis 147: 624, 1983.

6) Winston DJ, Ho WG, Nakao SL, Galew RP, Champlin RE. Norfloxacin versus vancomycin/polymyxin for prevention of infections in granulocytopenic patients. Am J Med 80: 884, 1986.

7) Winston DJ, Ho WG, Champlin RE, et al. Norfloxacin for prevention of bacterial infections in granulocytopenic patients. Am J Med 82: 40, 1987.

8) Karp JE, Merz WG, Hendricksen C, et al. Oral norfloxacin for prevention 


\section{NFLX/AMPH-B for Prevention of Infections}

of gram-negative bacterial infections in patients with acute leukemia and granulocytopenia. Ann Int Med 106: 1, 1987.

9) Del Favero A, Menichetti F, Martino P, et al. Prevention of bacterial infection in neutropenic patients with hematologic malignancies. Ann Intern Med 115: 7, 1991.

10) Verhoef J, Rozenberg-Arska M, Dekker A. Prevention of infection in patients with acute nonlymphocytic leukemia by several drug treatment regimens. Haematol Blood Transfusion 30: 188, 1987.

11) Gunther I, Kaben U, Brijmohan-Gunther R, Konrad H. Selective decontamination of the digestive tract and fungal infection in acute leukemia patients. Recent Results Cancer Res 108: 82, 1988.

12) Urabe A, Takaku F, Mizoguchi H, et al. Prophylactic and therapeutic effects of oral administration of amphotericin B in mycosis associated with hematologic disease. Jpn J Antibiot 43: 116, 1990.

13) Schimpff SC, Greene WH, Young VM, et al. Infection prevention in acute nonlymphocytic leukemia: Laminar air flow room reverse isolation with oral, nonabsorbable antibiotic prophylaxis. Ann Intern Med 82: 351, 1975.

14) Munier-Carpentier F, Kiehn TE, Armstrong D. Fungemia in the immunocompromised host. Changing patterns, antigenemia, high mortality. Am J Med 71: 363, 1981.

15) Wade JC, Schimpff SC, Hargadon MT, et al. A comparison of trimethoprim-sulfamethoxazole plus nystatin with gentamicin plus nystatin in the prevention of infections in acute leukemia. N Engl J Med 304: 1057,
1981.

16) Ezdili EZ, O'Sullivan DD, Wasser LP, et al. Oral amphotericin for candidiasis in patients with hematologic neoplasms. J Am Med Assoc 242: $258,1979$.

17) Suda T, Omine M, Tsuchiya J, et al. A co-operative study on prophylaxis of fungal infection in patients with hematological diseases: Prophylactic effect of oral administration of amphotericin B. Jpn J Clin Hematol 21: $195,1980$.

18) Moriuchi $Y$, Kamihira S, Yamaguchi K, et al. Bacteriological study on autopsied cases with hematological malignancies, particularly the increased isolation of fungus and gram-positive cocci. Jpn J Clin Hematol 27: 2085, 1986.

19) DeGregorio MW, Lee WMF, Ries CA. Candida infections in patients with acute leukemia: Ineffectiveness of nystatin prophylaxis and relationship between oropharyngeal and systemic candidiasis. Cancer 50: 2780, 1982.

20) van derWaaijD, Berghuis JM. Selective elimination of Enterobacteriaceae species from the digestive tract in mice and monkeys. J Hyg 72: 205, 1974.

21) Vangdal $M$, Bergan T. In vitro synergistic activity of norfloxacin and amphotericin B against fungi. Drugs Exp Clin Res X (7): 443, 1984.

22) Hughes WT, Feldman S, Gigliotti F, et al. Prevention of infectious complications in acute lymphoblastic leukemia. Semin Oncol 12: 180, 1985. 